\title{
Malignant Pancreatic Insulinoma
}

National Cancer Institute

\section{Source}

National Cancer Institute. Malignant Pancreatic Insulinoma. NCI Thesaurus. Code C65186.

An insulin-producing neuroendocrine tumor arising from the beta cells of the pancreas.

Patients exhibit symptoms related to hypoglycemia due to inappropriate secretion of insulin. It displays vascular invasion and metastasizes to other anatomic sites. 